\title{
An Application of Hybrid Method For Improving Of Ignition System In Small Power Explosion Engine
}

\author{
LE Khanh Dien [1], Tan-Le Khanh [2], Dung-Do Van [2], Am-Do Quoc[2] \\ [1]The Ho Chi Minh City University of Technology, HCMUT \\ [2]The Ho Chi Minh City University of Technical Education, HCMUTE
}

\begin{abstract}
In spark ignition engine (SI engine), the mixture of air and fuel is usually formed outside of the cylinder and ignited by a spark plug. Basing on the way of energy-accumulation, there are two types of ignition systems: capacitive discharge ignition system (CDI) and transistorized ignition system (TI). Although the two types of ignition system are different, they have provided the same high-voltage pulse. This paper attempts to represent a hybrid ignition system that could be used in two distinct types of ignition system with a programmable controller. According to the range of activation of the engine, the controller automatically select between CID or TI system in the optimization of consumption of fuel.
\end{abstract}

Experiment results of the research shows that the hybrid ignition system could reduce the fuel consumption up to $55 \mathrm{~g}$ per $100 \mathrm{~km}$. The $\mathrm{CO}$ and $\mathrm{HC}$ levels are also reduced to $0.02 \%$.

Keywords: Capacitive Discharge Ignition System, Transistorized Ignition System, Ignition Energy And Hybrid Ignition System.

\section{Introduction}

So far, on the spark ignition engine, capacitive discharge ignition system and transistorized ignition system are only two types of ignition systems that are commonly used. The most important advantage of transistorized ignition system is the spark lifetime quite long ${ }^{[1]}$. This is because initially, the ignition energy requirement is just enough to pass over the spark plug gap. However, the current growth in the primary coil is relatively slow. So, when an engine working at high speed, it is risked that the ignition energy is not able to get the needed value for creating spark. Meanwhile, at low speeds, the current will exist so long that will make the primary coil overheating and waste energy.

With the advantage of fast increase in secondary voltage [1], capacitive sparks can easily make fuel mixture catch fire especially when the combustion chamber get too much oil deposit, the mixture is too rich or in low temperature. Another key advantage is that the charging and discharging time of the capacitor is very short, so it is guaranteed to be always sufficient energy when the engine cranking at high speed ${ }^{[1]}$. However, the discharged cycle happens so fast, the energy depletion converges quickly causing short spark duration. Therefore, it is difficult to burn the mixture in some special cases. For example, a lean fuel condition ${ }^{[2]}$.

We have seen that the drawbacks of any kind of ignition system are only affecting some particular domains work of engine. Moreover, for the two types of ignition system, the advantages of this system are almost the disadvantages of the other and vice versa. Therefore, the study of a hybrid ignition system that could apply in both types if ignition is very important.

\section{Analyzing processes \\ A. Analyze the ignition system in Honda Wave RS.}

On Honda Wave RS engine, there are three signals generated from the flywheel assembly coils, which are charging signal, high voltage signal to the charge the capacitor and the timing signal pulse at each $360^{\circ}$ BTDC.

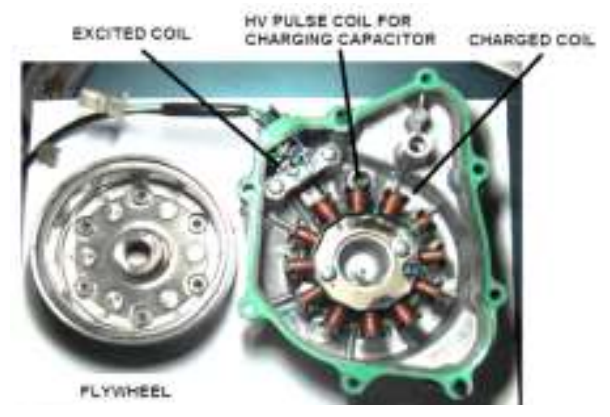

Figure 1: Flywheel assembly coils of Honda Wave RS

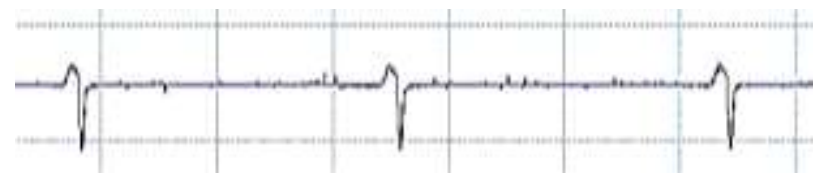

Figure 2: The signal pulse emitted by the crankshaft position sensor

\section{B. Analyze the capacitor charging voltage pulse of CDI.}

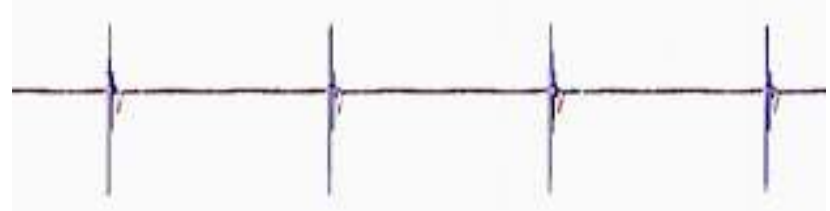

Figure 3: High voltage pulse waveform of primary winding coil of CDI

The voltage value at the top of the first pulse is the highest value of the capacitive voltage that was charged before launching through the primary winding coils ${ }^{[3]}$. 
Proc. of the Intl. Conf. on Advances in Civil, Structural and Mechanical Engineering - ACSM 2015. Copyright (@) Institute of Research Engineers and Doctors, USA .All rights reserved.

ISBN: 978-1-63248-039-2 doi: 10.15224/ 978-1-63248-039-2-20

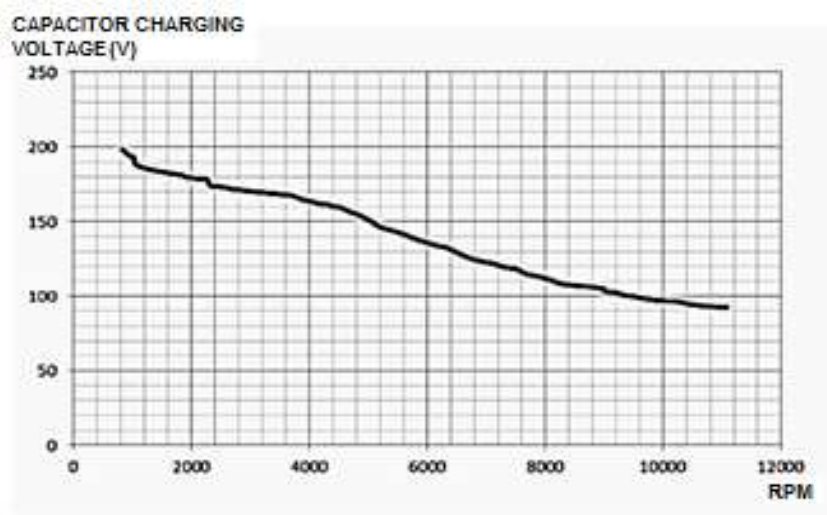

Figure 4: Capacitive voltage changing with engine revs.

Inside the Honda's ignition igniter, main capacitor is $225 \mathrm{~K} 400$. This capacitor is $2.2 \mu \mathrm{F}$ and the charging voltage peak is $400 \mathrm{~V}$.

With the ignition energy equation:

$$
\mathrm{W}=\frac{C U^{2}}{2}(\mathrm{~J})
$$

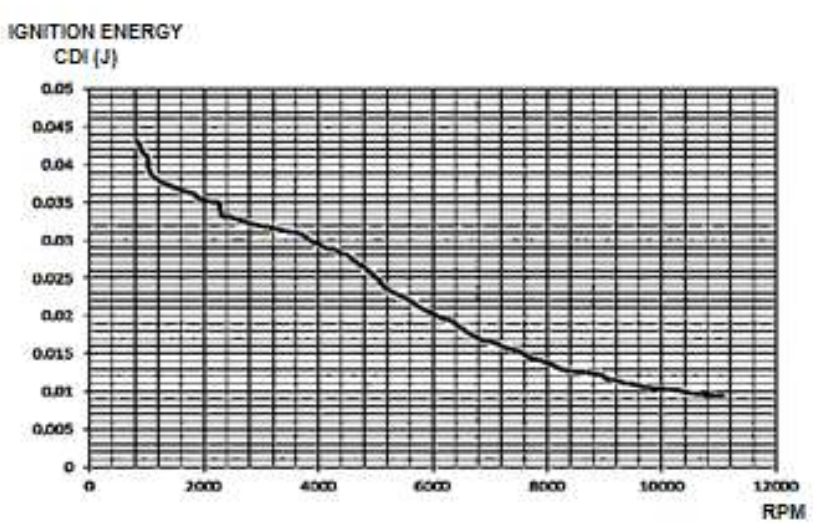

Figure 5: Capacitive energy change with engine revs

\section{c. Analyze the ignition coils on a Honda Wave RS}

The parameters of the ignition coil are displayed below.

$\mathrm{R}_{1}=0.8 \Omega, \mathrm{R}_{2}=12700 \Omega$

$\mathrm{L}_{1}=2 \mathrm{mH}, \mathrm{L}_{2}=16.5 \mathrm{H}$

The relationship between the numbers of winding turns and the inductance is:

$\frac{\mathrm{N}_{2}}{\mathrm{~N}_{1}}=\sqrt{\frac{\mathrm{L}_{2}}{\mathrm{~L}_{1}}}=\sqrt{\frac{16.5}{0.002}} \approx 91$

The waveforms of the primary voltage:

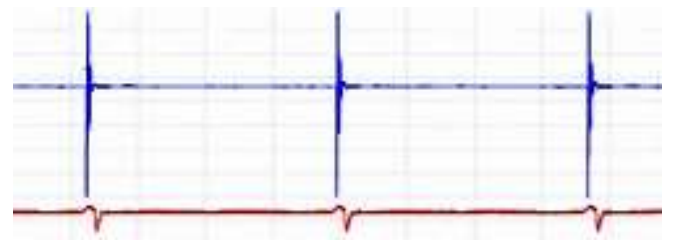

Figure 6: Relationship between voltage waveform of capacitive ignition and crankshaft position sensor.

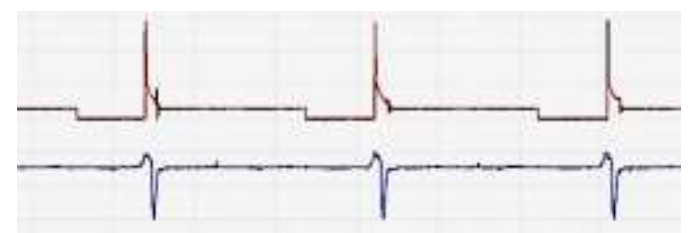

Figure 7: Relationship between voltage waveform of transistorized ignition and crankshaft position sensor.

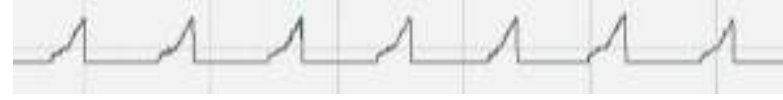

Figure 8: Current builds in the primary coil when the power transistor switched on.

I prolong the dwelling time until the current building through the primary coil reaches the saturation value.

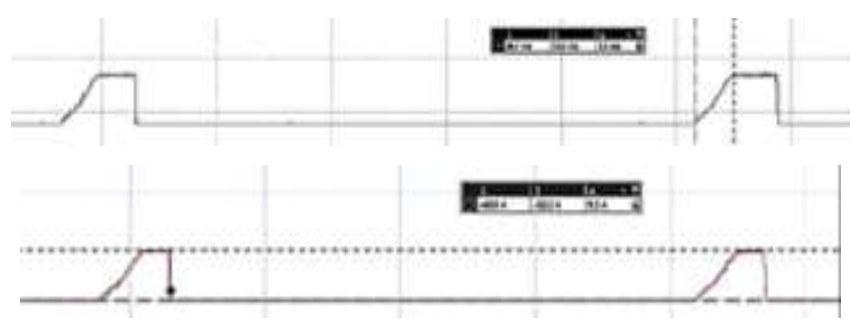

Figure 9: Current growth through primary winding derives to saturation

From the measurement data, we have the minimum time for current to reach the maximum value of $9.3 \mathrm{~A}$ is $3.3 \mathrm{~ms}$.

$\mathrm{T}_{\text {Emax }}=3.3 \mathrm{~ms}$.

To ensure the power transistor in transistorized ignition igniter steady work, no overheating, we choose the ratio between the maximum dwelling time and minimum ignition cycle is $2 / 3^{[3]}$.

$$
\frac{\mathrm{T}_{\mathrm{dwellmax}}}{\mathrm{T}_{\min }}=\frac{2}{3}
$$

When $\mathrm{T}_{\mathrm{dw} \text { llmax }}=\mathrm{T}_{\mathrm{Emax}}$ the ignition cycle is at minimum value $\left(\mathrm{T}_{\min }\right)$ which corresponds to the engine's rpm at highest RPM (ne max $_{\text {) }}$.

$$
\begin{aligned}
& \mathrm{T}_{\text {min }}=\frac{3 * \mathrm{~T}_{\mathrm{Emax}}}{2}=\frac{3 * 3.3}{2} \approx 5 \mathrm{~ms} \\
& \mathrm{n}_{\mathrm{e} \max }=\frac{60}{T_{\min }}=\frac{60 * 1000}{5}=12000 \mathrm{rpm}
\end{aligned}
$$

The Honda Wave RS achieves maximum power of 5.5 $\mathrm{kW}$ at $8000 \mathrm{rpm}$. Therefore, if we switch the ignition system to the transistorized ignition system type, it will not affect the capability of engine's power. 
Proc. of the Intl. Conf. on Advances in Civil, Structural and Mechanical Engineering - ACSM 2015. Copyright (@) Institute of Research Engineers and Doctors, USA .All rights reserved.

ISBN: 978-1-63248-039-2 doi: 10.15224/ 978-1-63248-039-2-20

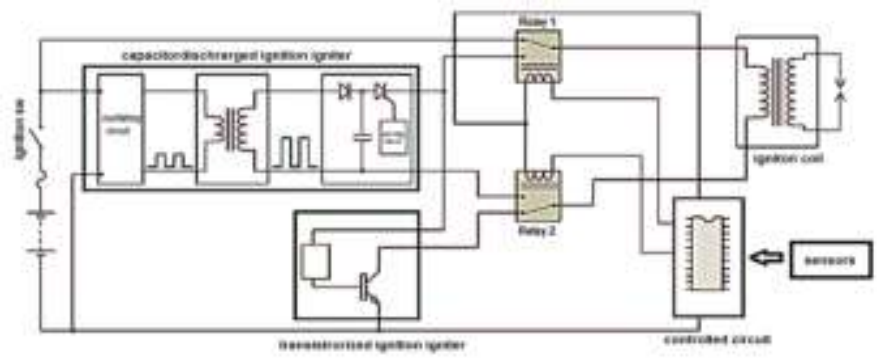

Figure 10: Diagram of hybrid ignition system installed on Honda Wave RS.

\section{Select the timing of ignition switching circuit.}

According to [5], there are three key points that help to determine what type of spark is more suitable for each working ranges of engine.

\section{a. Pressure inside the cylinder}

If the pressure inside the cylinder is high, the resistance between spark plug's gaps will increase. Therefore, it requires a higher ignition voltage than normal to cause spark. At this time, the engine is working in heavy load or in acceleration. With the characteristic of fast growth in secondary voltage ${ }^{[3]}$, capacitive park is more suitable for engine at this time.

\section{b. Air fuel ratio}

The rate of fuel mixture inside the cylinder is not constancy. It will continuously vary according to the engine load.

Table 1: Fuel mixture ratio under the regime of the load in an engine ${ }^{[3]}$

\begin{tabular}{|c|c|c|}
\hline No & Engine working range & Air fuel ratio \\
\hline $\mathbf{1}$ & Cold start $\left(0^{\circ} \mathrm{C}\right)$ & $1: 1$ \\
\hline $\mathbf{2}$ & Normal start $\left(20^{\circ} \mathrm{C}\right)$ & $5: 1$ \\
\hline $\mathbf{3}$ & Fast idle & $10: 1$ \\
\hline $\mathbf{4}$ & Idle & $11: 1$ \\
\hline $\mathbf{5}$ & Low load & $12-13: 1$ \\
\hline $\mathbf{6}$ & Medium load & $16-18: 1$ \\
\hline $\mathbf{7}$ & High load & $12-13: 1$ \\
\hline $\mathbf{8}$ & Accelerations & $8: 1$ \\
\hline
\end{tabular}

When the mixture is rich $(\mathrm{A} / \mathrm{F}<14.7)$, it is easy to propagate the flame. Therefore, it only needs a small spark with short duration to trigger fire. Otherwise, when mixture is poor $(\mathrm{A} / \mathrm{F}>14.7)$, the molecules of air and fuel are set wide apart. Therefore, they require a longer spark to ignite the mixture ${ }^{[2]}$.
Capacitive spark should be more appropriate for the engine of rich mixture range. In average load range, the air fuel is relatively poor. With the featuring of secondary voltage pulse slowing growth and survival time sparks long ${ }^{[4]}$, transistorized ignition type is the best use for this mode.

\section{c. Engine speed}

When the engine is at high speed, the time for an ignition cycle will decreased. If we use transistorized ignition system, the dwell timing has to be reduced accordingly. Therefore, the current cannot get to the demanded value to cause the spark. In this case, capacitive discharged ignition system will fit the engine operation at high RPMs.

\subsection{Controller board designed ignition system combines}

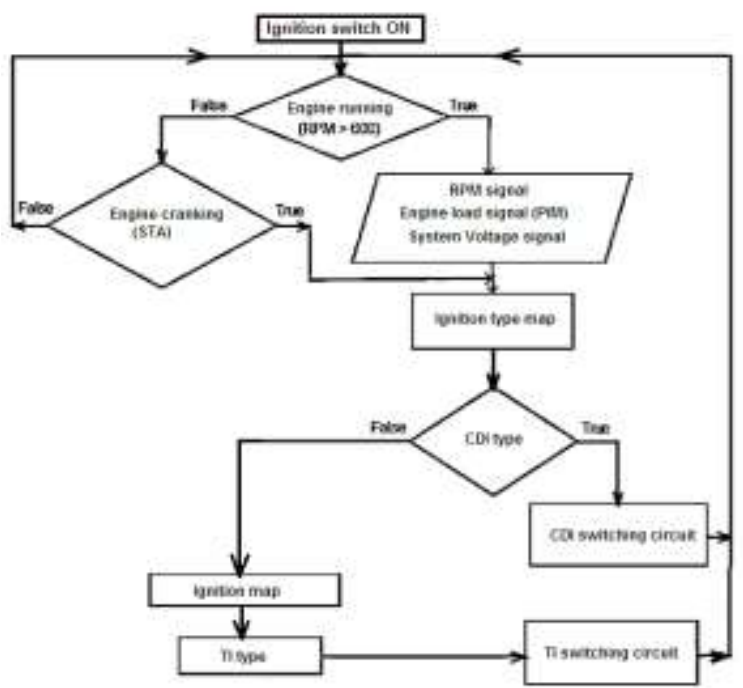

Figure 11: The algorithm controls the ignition switch
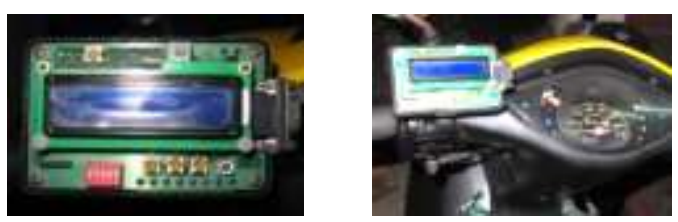

Figure 12: Control main board assembly and mounting on the vehicle.

\subsection{Test operation of the system.}

a. Check the secondary Voltage waveform when the hybrid ignition system switching circuit.

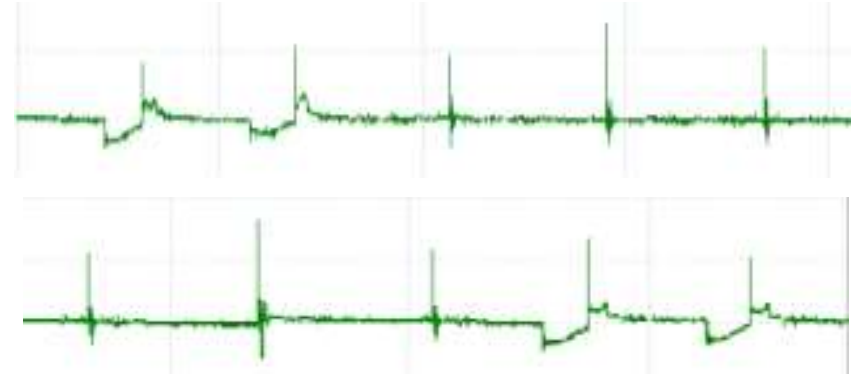

Figure 13: Secondary Voltage at the time of switching circuit from TI to $\mathrm{CDI}$ and $\mathrm{CDI}$ to TI ignition type 
Proc. of the Intl. Conf. on Advances in Civil, Structural and Mechanical Engineering - ACSM 2015. Copyright (@) Institute of Research Engineers and Doctors, USA .All rights reserved.

ISBN: 978-1-63248-039-2 doi: 10.15224/ 978-1-63248-039-2-20

The switching circuit works smoothly and does not cause any voltage spike or interference to electronic devices.

\section{b. Measurement of fuel consumption}

Fuel consumption is tested at internal combustion engine laboratory in the University of Technology Ho Chi Minh City. At that time, Honda Wave RS produced in 2005 had an odometer reached $67000 \mathrm{~km}$. Gasoline used to test is A95.

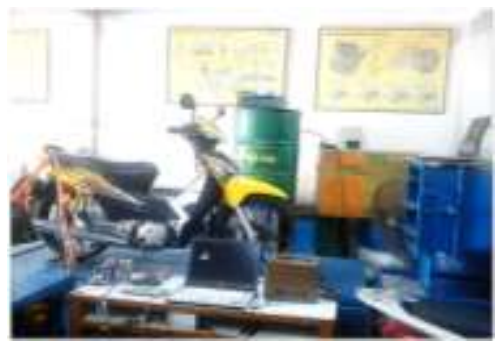

Figure 14: Honda Wave RS is mounted on a dynamometer.

Table 2: Parameters measured using the ignition system combines TI - CDI.

\begin{tabular}{|c|c|c|}
\hline \multicolumn{2}{|c|}{ Date $13 / 1 / 2014$} \\
\hline Start time $\quad: 10: 43: 11 \mathrm{AM}$ \\
\hline \multicolumn{2}{|c|}{ End time $10: 51: 41 \mathrm{AM}$} \\
\hline \multicolumn{3}{|c|}{ No. of driving errors : 24} \\
\hline \multicolumn{2}{|c|}{ Travel distance $: 4294 \mathrm{~m}$} \\
\hline m1 & 806.5 & $\mathrm{~g}$ \\
\hline m2 & 745 & $\mathrm{~g}$ \\
\hline $\begin{array}{c}\text { Fuel } \\
\text { Consumption }\end{array}$ & $\mathbf{6 1 . 5}$ & $\mathrm{g}$ \\
\hline
\end{tabular}

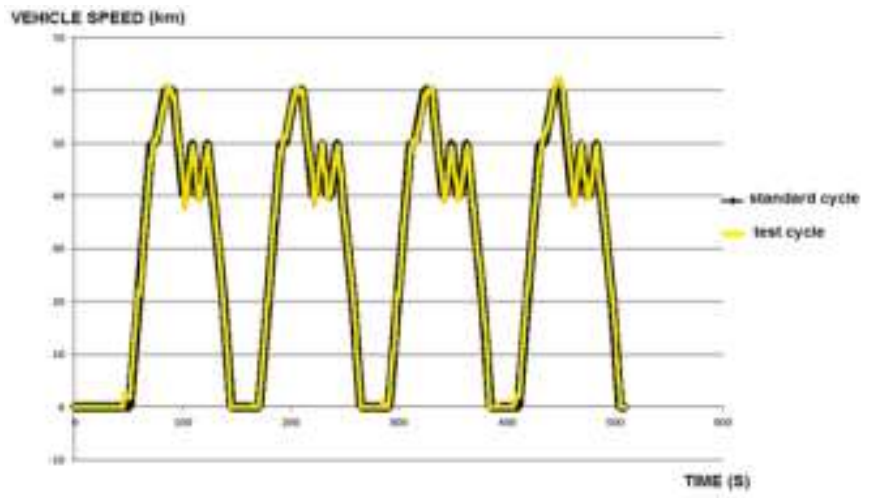

Figure 15: The correlation between the actual speed and the speed of standard cycle using the hybrid ignition system.

Table 3: Parameters measured using the standard capacitive discharge ignition.

\begin{tabular}{|c|c|c|}
\hline \multicolumn{3}{|c|}{ Date $3 / 1 / 2014$} \\
\hline \multicolumn{3}{|c|}{ Start time $: 10: 59: 21 \mathrm{AM}$} \\
\hline \multicolumn{3}{|c|}{ End time $11: 07: 51 \mathrm{AM}$} \\
\hline \multicolumn{3}{|c|}{ No. of driving errors : 9} \\
\hline \multicolumn{3}{|c|}{ Travel distance $: 4102 \mathrm{~m}$} \\
\hline m1 \\
\hline m2
\end{tabular}

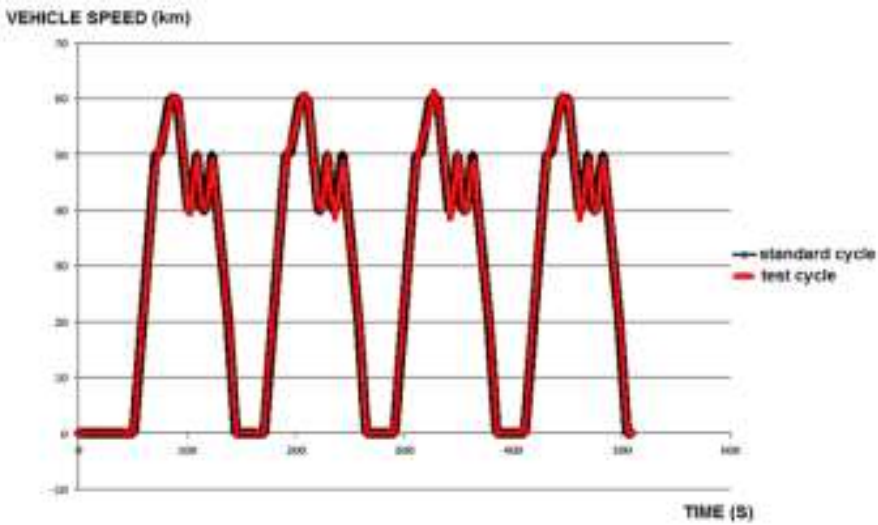

Figure 16: The correlation between the actual speed and the speed of standard cycle using the original ignition system CDI

Although the fuel consumption is somewhat higher of $0.5 \mathrm{~g}$ but the distance traveled is farther $(4294 \mathrm{~m}$ than $4102 \mathrm{~m}$ ) when I used hybrid ignition system. From here, the amount of fuel consumed per 100 kilometers when using hybrid ignition system and capacitive discharge ignition system are $1432.23 \mathrm{~g}$ and $1487.08 \mathrm{~g}$ respectively. Therefore, we can conclude that the amount of fuel consumption when using the hybrid ignition system is less than $55 \mathrm{~g} / 100 \mathrm{~km}$ in comparison with using traditional ignition system.

\section{c. Emission testing}

Emission measurement was carried out at gasoline engines workshop of University of Technical Education Ho Chi Minh City. Testing device for measuring emissions is exhaust gas analyzer Horiba MEXA - 324L. This device can analyze the two kinds of air, which are $\mathrm{CO}$ and $\mathrm{HC}$.

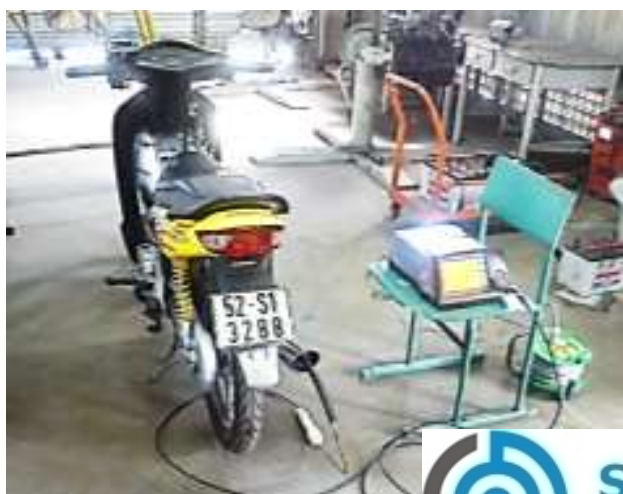


Proc. of the Intl. Conf. on Advances in Civil, Structural and Mechanical Engineering - ACSM 2015.

Copyright (C) Institute of Research Engineers and Doctors, USA .All rights reserved.

ISBN: 978-1-63248-039-2 doi: 10.15224/ 978-1-63248-039-2-20

Figure 17: Smoke emissions measuring equipment connected to the exhaust pipe
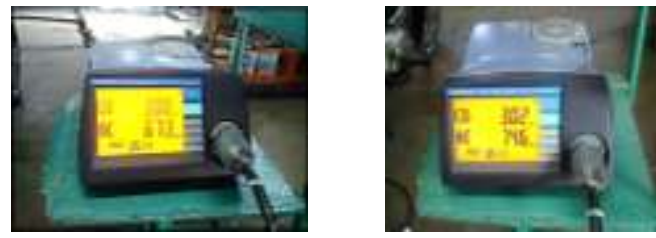

Figure 18: Parameters measured emission results when using TI - CDI ignition and overseas original CDI ignition.

For CO level, we found almost no significant differences when we change the ignition type. However, the application of the hybrid ignition system, the HC level is significantly lower than when using CDI ignition type. This is due to time sparks exist longer than one of CDI, that help to burn out completely the mixture and to reduce the $\mathrm{HC}$ emission.

\section{Conclusion}

The use of the correct ignition type gets more efficiency to the engine, reduces environmental pollution.

The practical tests have given out some positive results, which are shown that the hybrid ignition system can help consume less fuel and reduce certain of exhaust level. The switching circuit controlled board has worked stable and precision. This subject has taken a completely new direction for research and practical when applied on a motorbike.
We would like to appreciate highly the great aid of the Laboratory of National key Lab of National University, B3, The HCM University of Technology.

\section{Acknowledgment}

\section{REFERENCES}

[1] Gianni Regazzi, Funo Di Argelato, Italy Beniamino Baldoni; Transistorized ignition system for internal combustion engines, USA Patent No. U.S. 7028676 B2, 2006.

[2] M.A Kalam, H. H. Masjiuki, M.A. Maleque, M.A. Amalina, H. Abdesselam, T. M. I. Mahlia, "Air -Fuel Ratio Calculation for a Natural Gas Fuelled Spark Ignition Engine" SAE Technical Paper 2004-01-0640, 2004.

[3] Do Van Dung, Electrical and Electronic Equipment on modern cars, published by the National University of Ho Chi Minh City, 2004.

[4] Shingo Morita, Takafumi Narishige, Mitsuru Koiwa; capacitive discharge ignition system with transistorizedly extended time; USA Patent No. 5220901, 1993.

[5] Dinh Ngoc An, Electric Car Equip tractors, publisher universities and professional schools, Hanoi, 1980.

About Author (s):

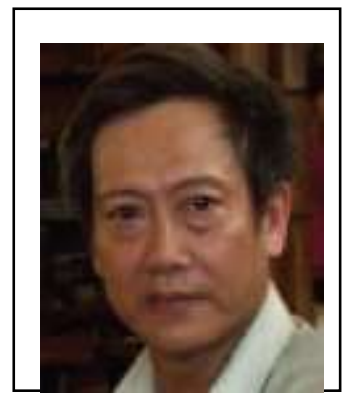

Author: LE Khanh Dien,

M.Eng, Senior lecturer of Faculty of Mechanical Engineering, The University of Technology (HCMUT) Address: 268 Ly Thuong Kiet, District 10, Ho Chi Minh City, Vietnam;

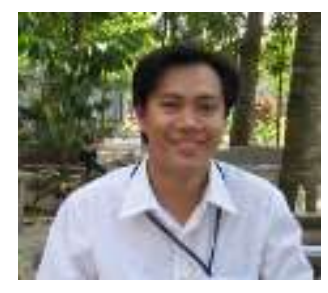

Author, Oral Presenter: LE Khanh Tan,

M.Eng, lecturer of Faculty Vehicle and Energy Engineering, The University of Technical Education (HCMUTE) Address: 1 Vo Van Ngan, Thuduc District, Ho Chi Minh City, Vietnam; 